\title{
ARTIGO DE REVISÃO \\ Fragilidades e potencialidades vivenciadas pela equipe de saúde no processo de transplante de órgãos: revisão integrativa
}

\author{
Weaknesses and capabilities experienced by a healthcare team in the organ \\ transplant process: integrative review
}

\author{
Carla Vieira Amante Senna ${ }^{\text {(D), Tatiana Martins }}$ (D), Neide da Silva Knihs $^{1}$ (D), \\ Aline Lima Pestana Magalhães ${ }^{1}$ (D), Sibele Maria Schuantes Paim² (D)
}

\section{RESUMO}

Avaliar as fragilidades e potencialidades vivenciadas pelos profissionais das unidades de pacientes críticos frente às etapas do processo de doação de órgãos. Revisão integrativa, desenvolvida em seis bases de dados, entre 2015 e 2020, nos idiomas inglês, português e espanhol. Foram selecionados 15 artigos. As informaçôes foram agrupadas em duas categorias temáticas: conhecimento da equipe no processo de doação; complexidade do processo de doaçáo de órgáos: aspectos emocionais nesse processo. As evidências apontam como principais fragilidades a pouca capacitação da equipe e estrutura das organizações de saúde. Quanto às potencialidades, destacam-se o reconhecimento das etapas e dos critérios para o diagnóstico de morte encefálica e a certificaçấo do direito da família em receber informaçôes sobre todas as etapas do processo de doação. Frente aos achados, a promoção de açôes de educaçáo permanente surge como estratégia efetiva para aprimorar a prática clínica neste processo.

Descritores: Obtenção de Tecidos e Órgãos; Transplante; Cuidados Críticos; Equipe de Assistente ao Paciente; Enfermagem.

\section{ABSTRACT}

The aim of this study is to evaluate the weaknesses and capabilities experienced by professionals working in critical care units during the stages of the organ donation process. This is an integrative review, developed using six databases, between 2015 and 2020, in English, Portuguese, and Spanish. A total of 15 articles were selected. The information was grouped into two thematic categories: team knowledge on the organ donation process; complexity of the organ donation process: emotional aspects of the process. The evidence indicates lack of training of the team and lack of structure of the healthcare organizations as the main weaknesses. Regarding the capabilities, recognition of the stages of and criteria for the diagnosis of brain death and guaranteeing the right of the family to receive information on all the stages of the transplant process stand out. Given the findings, promoting actions of continuing education emerges as an effective strategy to improve clinical practice in this process.

Descriptors: Tissue and Organ Procurement; Transplantation; Critical Care; Patient Care Team; Nursing.

\footnotetext{
${ }^{1}$ Universidade Federal de Santa Catarina - Florianópolis (SC), Brasil. E-mails: cvsenna@hotmail.com, tatiana martins15@hotmail.com, neide.knihs@ufsc.br, aline.pestana84@gmail.com

${ }^{2}$ Universidade Federal de São Paulo - São Paulo (SP), Brasil. E-mail: sibele.schuantes@hotmail.com
}

Como citar este artigo: Senna CVA, Martins T, Knihs NS, Magalhães ALP, Paim SMS. Fragilidades e potencialidades vivenciadas pela equipe de saúde no processo de transplante de órgãos: revisão integrativa. Rev. Eletr. Enferm. [Internet]. 2020 [acesso em: org $/ 10.5216 /$ ree.v22.58317. ];22:58317. Disponível em: https://doi. 


\section{INTRODUÇÃO}

O processo de doação de órgãos e tecidos é complexo por envolver diferentes etapas, sendo a identificação e validação do potencial doador, diagnóstico de Morte Encefálica (ME), manutenção do potencial doador, entrevista familiar para doação de órgãos, logística no processo de retirada, distribuição dos órgãos e liberação do corpo ${ }^{(1)}$. Neste cenário, a equipe das unidades de pacientes críticos atua em praticamente todas as etapas, com exceção da logística da retirada e distribuição dos órgãos ${ }^{(2)}$.

Ao longo dos anos, estudos têm mostrado as fragilidades e potencialidades das equipes alocadas nessas unidades. No que se refere às fragilidades, pontua-se a subnotificação de potenciais doadores relacionada à dificuldade em validar pacientes com critérios clínicos de $\mathrm{ME}$, falta de preparo para conduzir o diagnóstico de ME e manutenção hemodinâmica do potencial doador. Ainda, ressaltam-se dificuldades na definição das contraindicaçôes para doação, comunicação da abertura do protocolo de ME e comunicação da morte para a família. Quanto às potencialidades, o envolvimento dos profissionais para notificar pacientes com diagnóstico de ME busca por aprimoramento na condução do processo e fortalecimento da equipe para tornar o processo ativo ${ }^{(2-4)}$.

A equipe de saúde das unidades de pacientes críticos (serviço de emergência e unidades de terapia intensiva) que atua neste processo necessita de conhecimento e habilidade para a condução de todas as etapas. Somente assim, é possível que haja um processo rápido, ágil, efetivo e de qualidade evitando perda de potenciais doadores, eventos adversos e consequentemente, problemas no transplante ${ }^{(3-5)}$.

No Brasil, cerca de 25\% dos órgãos para transplantes são irrecuperáveis por problemas relacionados ao gerenciamento das etapas de cuidados intensivos no período vital e crítico do potencial doador nas Unidades de Pacientes Críticos (UCIs) (6). Dentre os principais problemas referentes a essas perdas, identifica-se a subnotificação de potenciais doadores e a parada cardíaca. Em números absolutos, aproximadamente, 4.000 possíveis doadores não são notificados pelos profissionais das UCIs e 3.700 potenciais doadores são perdidos anualmente ${ }^{(6-8)}$. Junto a isso, mais de 4.500 famílias recusam a doação de órgãos a cada ano, tendo como um dos principais motivos: a não compreensão do diagnóstico de $\mathrm{ME}$ e a desconfiança no processo de doação ${ }^{(9,10)}$.

Quando o paciente apresenta sinais clínicos de ME, ou seja, perda completa e irreversível das funçóes encefálicas, definida pela cessação das atividades corticais e de tronco encefálico ${ }^{(1)}$, uma série de alterações fisiológicas são desencadeadas, não havendo compensação do próprio organismo para lidar com tais alteraçôes. Nesse momento, é fundamental que a equipe das UCIs atue de maneira rápida, efetiva e segura, oferecendo todos os cuidados definidos pelas diretrizes da Associaçáo de Medicina Intensiva Brasileira (AMIB). Ainda, diante da evolução da $\mathrm{ME}$, é necessário que a equipe comunique a família de maneira clara e simples como se desenvolve o protocolo de $\mathrm{ME}$, conforme legislaçáo vigente no país. De acordo com o decreto 2.175, este diagnóstico deve ser realizado por dois médicos com intervalo de uma hora para cada exame clínico, sendo necessária a realização de um exame complementar ${ }^{(1,9,11)}$.

Diante do exposto, compreende-se como indispensável conhecer as fragilidades e potencialidades destes profissionais nas atividades de identificação e validação do possível doador, diagnóstico de $\mathrm{ME}$, manutenção do potencial doador, comunicação do protocolo de ME e comunicação da morte, em razão dos números expressivos de perdas de potenciais doadores que, ainda, ocorrem em nosso país. Por meio das informaçóes obtidas nesse estudo, acredita-se ser possível desenvolver melhorias no cenário da doação e aprimoramento da equipe de saúde. Haja vista que ao conhecer as fragilidades e potencialidades destes profissionais, gestores governamentais e não governamentais poderão propor estratégias efetivas direcionadas a essa realidade.

Frente a isso, entende-se que o impacto do estudo está direcionado a propor açóes de melhorias no cenário da prática do processo de doação de órgãos, tornando essas atividades mais seguras, efetivas, com menor risco de danos aos profissionais, potenciais doadores, família e pacientes que irão realizar o transplante.

Neste sentido, a questão norteadora do estudo é: Quais fragilidades e potencialidades são vivenciadas pelos profissionais que atuam nas Unidades de Pacientes Críticos na identificação e validação do possível doador, diagnóstico de morte encefálica, manutenção do potencial doador, comunicação do protocolo da morte encefálica à família e comunicação da morte?

Objetivo: avaliar as fragilidades e potencialidades vivenciadas pelos profissionais que atuam em Unidades de Pacientes Críticos frente às etapas do processo de doação de órgãos.

\section{MÉTODO}

Trata-se de uma revisão integrativa da literatura, desenvolvida a partir das etapas do Preferred Reporting Items para Revisóes Sistemáticas e Meta-Análises (PRISMA) ${ }^{(12)}$. Contudo, não foi possível concluir a revisão sistemática devido à não identificação de artigos que sustentassem esse tipo de revisão ao serem lidos na íntegra, visto que os níveis de evidências dos estudos eram fracos.

A pergunta de pesquisa foi elaborada considerando a estratégia PICO que representa um acrônimo para Paciente, Intervenção, Comparação e "Outcomes" (desfecho). A população do estudo foi: profissionais de saúde das Unidades de Pacientes Críticos; a Intervenção: atividades 
vivenciadas pelos profissionais quanto à validação do potencial doador, diagnóstico de morte encefálica e comunicação da morte; Comparaçáo: etapas do processo de doação de órgãos conforme legislação e diretrizes da Associação de Medicina Intensiva; Outcomes: fragilidades e potencialidades das Equipes que atuam em Unidades de Pacientes Críticos nas etapas do processo de doação de órgáos. $\mathrm{O}$ acrônimo Comparação não foi utilizado neste estudo. Dessa forma, a questáo norteadora elaborada foi: Quais fragilidades e potencialidades sáo vivenciadas pelos profissionais que atuam em Unidades de Pacientes Críticos na identificação e validação do possível doador, diagnóstico de morte encefálica, manutenção do potencial doador, comunicação do protocolo da morte encefálica à família e comunicação da morte?

As bases de dados foram definidas considerando a questáo norteadora, o objetivo e a temática, sendo elencadas as seguintes: Publisher Medline (PubMed), biblioteca virtual (ScientificEletronicLibrary Online-SciELO), The Cumulative Index to Nursing and Allied Health Literature (CINAHL), Literatura Latino-Americana e do Caribe em Ciências da Saúde (LILACS), Scopus e Web of Science. Para a estratégia de busca, foram utilizados os seguintes descritores: "Morte Encefálica/Brain Death/Muerte Encefálica; Transplante/ Transplantation/Trasplante; Obtenção de Tecidos e Órgão/ Tissue and Organ Procurement/Obtención de Tejidos y Organos; Terapia Intensiva/Intensive Care/Cuidados Intensivos; Unidades de Terapia Intensiva/Intensive Care Units/Unidades de Cuidados Intensivos; Pessoal de Saúde/ Health Personnel/Personal de Salud; Equipe de Assistência ao Paciente/Patient Care Team/Grupo de Atención al Paciente; Enfermagem/Nursing/Enfermeria; Médicos/ Physicians/Medicos". Destaca-se que para cada base de dados foi desenvolvida uma estratégia de busca juntamente com uma bibliotecária. $\mathrm{Na}$ sequência serão apresentadas as estratégias de busca de uma base de dados como exemplo (Quadro 1).
Cada revisor fez uma busca nas bases de dados de maneira independente para identificar artigos publicados entre 2015 e 2020. Após essa etapa, o material foi transferido ao gerenciador bibliográfico Mendeley ${ }^{\circledR}$, seguido com a leitura do título e dos resumos de maneira independente e cega por dois revisores (Revisor 1 e Revisor 2). Critérios de inclusão: artigos de pesquisas qualitativas, quantitativas, indexados nas bases de dados selecionadas, publicados nos idiomas português, espanhol ou inglês, entre 2015 e 2020. A opção por esse período foi em razão de buscar identificar possíveis fragilidades da equipe nos últimos anos neste cenário, a fim de que a evidência científica encontrada pudesse mapear os mais diversos cenários de atuação e ainda, sugerir estratégias que otimizem esse processo. Critérios de exclusão: artigos de revisão, relato de experiência, cartas, editoriais, resumo de anais e eventos, materiais publicados em outros idiomas que não sejam inglês, espanhol e português.

Ao término da leitura do título e resumo, realizou-se uma reuniáo com um terceiro revisor para chegar ao consenso dos artigos selecionados para leitura na íntegra. Nessa etapa, fez-se necessário a reavaliaçáo de 12 artigos os quais geraram dúvidas entre os dois revisores. Cada autor leu de maneira independente os manuscritos, sendo descartados aqueles que não estavam relacionados com a temática proposta. No intuito de identificar as informaçóes mais relevantes, um quadro foi elaborado com as seguintes variáveis: título, ano de publicaçáo, autores, periódico, base de dados, objetivo(s), tipo de estudo, nível de evidência, resultados e recomendaçóes.

Após a elaboração do quadro, os autores leram de maneira exaustiva as informaçôes obtidas identificando as características de cada artigo, bem como, os principais dados relacionados às potencialidades e dificuldades da equipe no cenário da doação de órgáos. Esta etapa foi realizada juntamente com dois colegas/autores com ampla expertise em unidades de terapia intensiva, cuidados a pacientes críticos e doação de órgãos, identificando informaçōes significativas do processo

Quadro 1. Estratégias de busca de acordo com a base de dados. Florianópolis, SC, Brasil, 2020.

\section{Base de Dados}

CINAHL

\section{Conjuntos de termos}

(Morte Encefálica OR Morte Cerebral OR Morte Clínica OR Brain Death OR Clinical Death OR Muerte Encefálica) AND (Transplante OR Transplantes OR Transplantação OR Enxertia OR Obtenção de Tecidos e Órgão OR Doação de Órgãos OR Doação de Órgão OR Doação de Tecido OR Doação de Tecidos e Órgãos OR Doador de Órgão OR Doador de Órgãos OR Doadores de Órgãos OR Transplantation OR Organ Donation OR Tissue donation OR Obtención de Tejidos OR Obtención de Tejidos y Órganos OR Obtención de Órganos) AND (Terapia Intensiva OR Unidades de Terapia Intensiva OR Cuidado Intensivo OR Cuidados Intensivos OR Cuidado crítico OR Cuidados Criticos OR Intensive Care OR Critical Care OR Intensive Care Units) AND (Pessoal de Saúde OR Profissional da Saúde OR Profissional de Saúde OR Profissionais da Saúde OR Profissionais de Saúde OR Equipe* OR Equipe de Assistência ao Paciente OR Enfermagem OR Enfermeir* OR Medico* OR Patient Care Team OR Health Personnel OR Nursing OR Nurse OR Nurses OR Physicians OR Personal de Salud OR Grupo de Atención al Paciente OR Enfermeria OR Enfermer*) 
de doação, bem como os melhores níveis de evidências. O Nível de Evidência (NE) foi classificado considerando: Nível 1: obtida por meio de meta-análise de estudos clínicos controlados e com randomização; Nível 2: obtidos por estudo com desenho experimental; Nível 3: delineamento de pesquisas quase experimentais; Nível 4: que emergem de estudos de coorte e de caso-controle delineados; Nível 5: que surgem de revisão sistemática de estudos descritivos e qualitativos; Nível 6: evidências derivadas de um único estudo descritivo ou qualitativo; e Nível 7: evidências oriundas de opinióes de autoridades ou relatório de comitê de especialistas ${ }^{(13)}$.

$\mathrm{Na}$ sequência, buscou-se desenvolver a interpretação e a síntese das informaçôes identificadas, comparando os dados obtidos na análise dos artigos, do mesmo modo que possíveis lacunas e viés de pesquisa, tendo como foco central da análise, identificar oportunidades para melhorias no cenário da doação.
Para melhor apresentação das informaçóes e compreensão do leitor, após análise, os dados obtidos foram agrupados por categorias conforme as etapas do processo de doação supracitadas: identificação e validação do potencial doador, diagnóstico de morte encefálica, manutenção do potencial doador e comunicação junto à família.

Foram identificados 1.161 artigos nas bases de dados, desses, 54 retirados por repetição. Foram lidos o título e o resumo de 1.107, dos quais 72 foram selecionados para leitura na íntegra. Após leitura na íntegra, 57 estudos foram excluídos, sendo que 48 não estavam relacionados com a pergunta PICO (não se relacionavam com profissionais que atuavam nas unidades de pacientes críticos), três foram excluídos por fragilidades no método (não deixavam claro o cálculo da amostra e como foi realizada a análise dos dados). Quatro eram artigos de revisão, dois eram de língua estrangeira diferentes do inglês e espanhol (Figura 1).

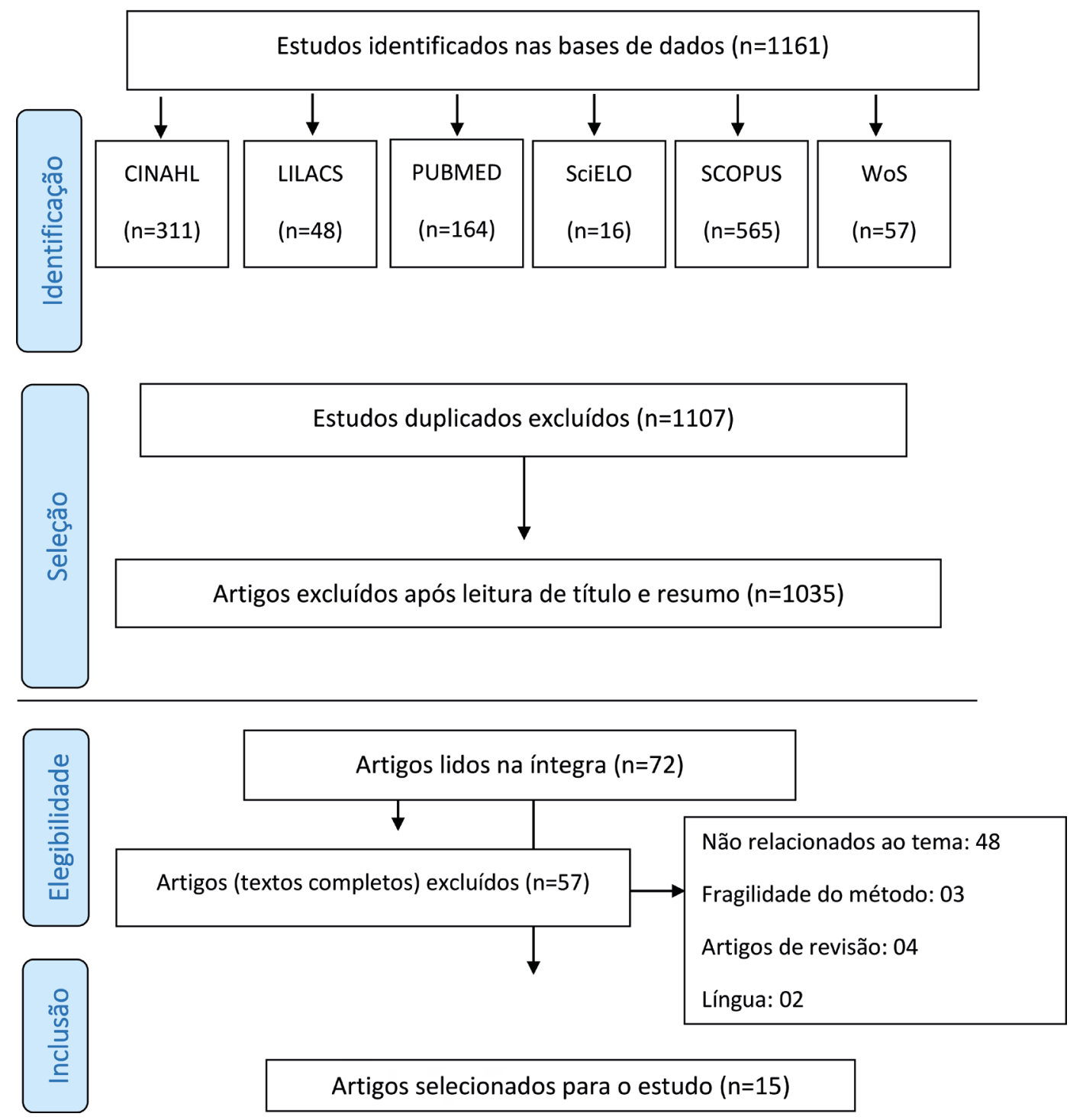

Figura 1. Diagrama PRISMA (12). Florianópolis, SC, Brasil, 2020. 


\section{RESULTADOS}

Quanto aos principais resultados, observa-se que a base de dados com maior número de publicaçôes analisadas na íntegra foi a PubMed, sete $(46,6 \%)$. O ano de 2018 destacou-se com o maior número de publicação sendo oito $(53,3 \%)$. Quanto ao nível de evidência, 13 $(86,6 \%)$ eram nível $6^{(13)}$. Todos os artigos foram obtidos gratuitamente em versão online. Para maior compreensão, o Quadro 2 apresenta as informaçóes obtidas nos artigos considerando o título, ano, nível de evidência, objetivo e principais resultados.

Os dados foram analisados e agrupados em três categorias, as quais serão apresentadas a seguir, no sentido de apresentar melhor as evidências para a prática profissional.

\section{Categoria 1: Conhecimento da equipe quanto as etapas do processo de doação}

Por meiodessa categoria, evidenciaram-seas potencialidades e as fragilidades relacionadas ao conhecimento da equipe quanto às etapas do processo de doaçáo. No que se refere às potencialidades, destaca-se a segurança da equipe, em especial dos enfermeiros, em identificar as causas de náo abertura do protocolo de $\mathrm{ME}^{(15)}$; Reconhecer o tempo adequado para realizaçáo dos exames e as etapas deste diagnóstico ${ }^{(15)}$; Admitir que a família tem direito de ser informada sobre a abertura do protocolo de $\mathrm{ME}^{(15)}$; Sentirem-se preparados para cuidar do paciente em $\mathrm{ME}^{(16)}$; Concordar que a ME equivale a morte ${ }^{(19)}$; Acolher a proposta de que o potencial doador é alguém que pode salvar vidas ${ }^{(22)}$.

Quadro 2. Síntese dos principais achados identificados nos estudos. Florianópolis, SC, Brasil, 2019.

\begin{tabular}{|c|c|c|}
\hline Título/ano/nível de evidência (NE) & Objetivo & Fragilidades (F) e potencialidades $(P)$ \\
\hline $\begin{array}{l}\text { Intensive Care Unites Nurses } \\
\text { Knowledge, Attitude, and Practice } \\
\text { Towards their Role in the Organ } \\
\text { Donation Process from Brain-Dead } \\
\text { Patients and Factors Influencing it } \\
\text { in Iran. 2015; (NE 5) }{ }^{\left({ }^{(4)} \text {. }\right.} \\
\end{array}$ & $\begin{array}{l}\text { Avaliar o conhecimento, atitudes e } \\
\text { práticas dos enfermeiros de Unidade } \\
\text { de Terapia Intensiva quanto ao seu } \\
\text { papel no processo de doação de órgãos } \\
\text { de pacientes com morte cerebral e } \\
\text { fatores que a influenciam no lrã. }\end{array}$ & $\begin{array}{l}\text { Enfermeiros atuam no processo sem ter um } \\
\text { papel definido (F); } \\
\text { Há enfermeiros que atuam no processo e não } \\
\text { estão de acordo com seus papéis (F); } \\
\text { Enfermeiros mostram pouco envolvimento } \\
\text { na prática deste processo (F). }\end{array}$ \\
\hline $\begin{array}{l}\text { Conhecimento do Enfermeiro no } \\
\text { Processo de Doação de Órgãos. } \\
\text { 2015; (NE 6)(15). }\end{array}$ & $\begin{array}{l}\text { Verificar o conhecimento do enfermeiro } \\
\text { no processo de doação de órgãos e } \\
\text { tecidos para transplantes. }\end{array}$ & $\begin{array}{l}\text { Enfermeiros reconhecem que a família tem o } \\
\text { direito de ser informada acerca do diagnóstico } \\
\text { de morte encefálica (P); } \\
\text { Enfermeiros reconhecem a hipotermia e o uso } \\
\text { de drogas depressoras do sistema nervoso } \\
\text { central como causas para a não abertura do } \\
\text { protocolo de morte encefálica (P); } \\
\text { Enfermeiros apresentam conhecimento } \\
\text { sobre o tempo adequado para realização } \\
\text { das avaliações no diagnóstico de morte } \\
\text { encefálica (P). }\end{array}$ \\
\hline $\begin{array}{l}\text { Conhecimento do enfermeiro na } \\
\text { manutenção do potencial doador de } \\
\text { órgãos e tecidos para transplante. } \\
\text { 2015; (NE 6)(16). }\end{array}$ & $\begin{array}{l}\text { Verificar o conhecimento dos } \\
\text { enfermeiros na manutenção do } \\
\text { potencial doador em morte encefálica, } \\
\text { diante das alterações hipotalâmicas, } \\
\text { hematológicas e dos aspectos } \\
\text { infecciosos. }\end{array}$ & $\begin{array}{l}\text { Enfermeiros se sentem preparados para } \\
\text { assistir aos pacientes em morte encefálica } \\
(85,4 \%)(P) ; \\
\text { Poucos enfermeiros (24,2\%) têm capacitação } \\
\text { para atuar no processo. A maioria }(87,8 \%) \\
\text { aprendeu na prática (F). }\end{array}$ \\
\hline $\begin{array}{l}\text { Fragilidades na atenção ao } \\
\text { potencial doador de órgãos: } \\
\text { percepção de enfermeiros. 2017; } \\
(\mathrm{NE} 6)^{(17)} \text {. }\end{array}$ & $\begin{array}{l}\text { Conhecer a percepção de enfermeiros } \\
\text { sobre fragilidades na atenção ao } \\
\text { potencial doador de órgãos. }\end{array}$ & $\begin{array}{l}\text { Falta apoio da instituição de saúde aos } \\
\text { profissionais que lidam com esse processo (F); } \\
\text { Faltam equipamentos e exames para } \\
\text { cuidados nesse processo (F); } \\
\text { Há dificuldades quanto ao espaço físico (F); } \\
\text { Alto grau de responsabilidade dos } \\
\text { enfermeiros no processo (P). }\end{array}$ \\
\hline
\end{tabular}


Quadro 2. Continuação.

\section{Título/ano/nível de evidência (NE)}

Clinicians' Perception and

Experience of Organ Donation From Brain-Dead Patients. 2017; (NE 6) ${ }^{(18)}$

Nurses' attitudes and knowledge
regarding organ and tissue
donation and transplantation in a
provincial hospital: A descriptive and
multivariate analysis. 2017; (NE 6)

\begin{tabular}{|l} 
\\
\hline Manejo dos pacientes em Morte \\
Encefálica. 2018; (NE 6) \\
\\
A morte que salva vidas: \\
complexidades do cuidado médico \\
ao paciente com suspeita de morte \\
encefálica. 2018 ; (NE 6)(22).
\end{tabular}

Descrever a percepção e experiência de médicos e enfermeiros sobre doação de órgãos em uma Unidade de Terapia Intensiva.

Determinarseatitudeseconhecimentos da equipe de enfermagem em relação à doação de órgãos e tecidos pode influenciar a decisão de tornar-se um doador. doadores.

Identificar o conhecimento dos enfermeiros da emergência e unidades de terapia intensiva em relação ao manejo do paciente em morte encefálica.

Compreender como os médicos do maior pronto-atendimento de uma metrópole brasileira orienta o cuidado aos pacientes graves com suspeita de morte encefálica e potenciais doadores
Fragilidades $(F)$ e potencialidades $(P)$

Um quinto da equipe relata que o processo de doação de órgãos é estressante $(F)$;

O envolvimento com a cultura da Unidade de Terapia Intensiva quanto ao diagnóstico de morte encefálica e doação, ainda é frágil (F);

(67\%) mencionam haver poucos treinamentos relacionados ao tema tornando esse momento estressante $(F)$;

Há pouco suporte na instituição de saúde, além de pouco ambiente positivo na condução do processo (F);

Profissionais mais antigos que atuam nesse processo tornam esse momento mais estressante $(F)$

O conhecimento dos enfermeiros precisa ser melhorado para garantir a funcionalidade do sistema de doação. Uma média superior a $46 \%$ errou as respostas $(F)$;

Há dúvidas da equipe quanto à funcionalidade do sistema de transplante $(F)$;

Os enfermeiros concordaram que a morte encefálica é equivalente à morte $(P)$.

Profissionais têm conhecimento que a declaração de morte encefálica é feita quando há perda irreversível da função cortical e do Avaliar o conhecimento dos tronco cerebral $(P)$;

profissionais da saúde que atuam na A sepse foi considerada contraindicação Unidade de Terapia Intensiva acerca do absoluta por grande parte dos participantes (F); diagnóstico de morte encefálica e da Houve dúvidas da equipe quanto à manutenção de órgãos em potenciais temperatura ideal de conservação do

potencial doador $(F)$;

$15 \%$ dos profissionais relataram dificuldades para apontar as etapas do protocolo de Morte Encefálica e cuidados ao potencial doador (F). de órgãos.
A equipe não inicia as manobras de reanimação caso exista parada cardíaca durante o diagnóstico (27,8\%) (F);

A equipe teve dificuldades em apontar cuidados relacionados à manutenção do doador (72,2\%) (F).

A equipe vê o potencial doador como alguém que pode salvar vidas $(P)$;

O cuidado ao potencial doador é visto como importante, mas sobretudo como sobrecarga de trabalho à equipe $(F)$;

A equipe, também, vê o cuidado ao potencial doador como velório no leito, visto que já está morto $(F)$;

A equipe apresenta dificuldades em explicar à família sobre a condição da morte encefálica (F). 
Quadro 2. Continuação.

\section{Título/ano/nível de evidência (NE)} diagnosis and management of the potential organ donor. 2018; (NE 6) (23).

Significados do cuidado de enfermagem ao paciente em morte encefálica potencial doador. 2018; $(\mathrm{NE} 5)^{(24)}$.

Explaining nurses' experiences of caring for brain dead patients: a content analysis. 2018; (NE 6)(25).
Objetivo

Identificar e discutir os diferentes significados e experiências de médicos e enfermeiros de uma Unidade de Terapia Intensiva Adulto em relação a manutenção do potencial doador de órgãos para transplante.

Compreender os significados do cuidado ao paciente em morte encefálica potencial doador para enfermeiros, e construir um modelo teórico.

Divulgar a experiência de enfermeiros que cuidam de pacientes em morte encefálica. ao diagnóstico de morte encefálica e

Fragilidades $(F)$ e potencialidades $(P)$

A equipe ainda tem dúvidas sobre o processo de doação, influenciada por crenças, cultura e educação de cada pessoa (F);

A equipe tem consciência sobre o diagnóstico de morte encefálica e doação, mas muitas vezes percebe que é deixado de lado pela sobrecarga de trabalho, condições de trabalho e cultura da equipe (F).

A equipe compreende a complexidade do cuidado ao potencial doador $(P)$;

Há distanciamento de parte da equipe de saúde na condução desse processo (F);

Reconhece a condição do cuidado ao paciente morto, mas com possibilidades de salvar vidas $(P)$

Papelfundamental do enfermeiro no atendimento do paciente em morte encefálica (P);

Dificuldades do enfermeiro nesse processo: estresse, sobrecarga emocional, medo e negligência $(F)$

Conflito da equipe quanto ao diagnóstico de morte encefálica, dificuldade e relutância em comunicar a morte encefálica e falta de apoio dos serviços de saúde $(F)$.

Desafios e tensões da equipe podem afetar na manutenção do potencial doador $(\mathbf{F})$;

Há necessidade de maior suporte de gestores ao profissional enfermeiro nesse processo, visto a complexidade do mesmo (F);

Incertezas do diagnóstico de morte encefálica (F); Conflitos com a equipe e a falta de apoio organizacional (F).

$55,3 \%$ deles consideraram a morte encefálica como morte (F).

Fatores associados com aqueles que consideram a ME encefálica como morte: experiências anteriores com diagnóstico de ME, cuidado desses pacientes em UTI, participação no processo de doação de órgãos (F).

Embora a maioria dos participantes converse com a família sobre ME, poucos relataram ter treinamento formal para esse momento (P/F). $72,4 \%$ manifestaram interesse em receber treinamento $(P)$.

Avaliar a compreensão da morte encefálica entre profissionais de saúde em unidades de terapia intensiva (UTI) em uma única instituição.
Apenas $18,0 \%$ assinalaram quais são os exames corretos para a ME (F).

Na análise multivariada, o maior acerto das questões, conhecimento sobre ME estava associada ao tempo de formação e treinamento $(P)$. 
Tais informaçóes revelam que a equipe de críticos, em especial os enfermeiros, estão aptos para atuar em atividades relacionadas aos critérios para iniciar o diagnóstico e cuidados ao paciente em $\mathrm{ME}^{(15,16)}$. Ser qualificado e sentir-se seguro nestas etapas é de extrema importância e relevância. Considerando tais conhecimentos da equipe, o risco de iniciar protocolo de ME antecipadamente são minimizados.

Quanto às fragilidades identificadas nessa categoria, pontuam-se as dificuldades para validar critérios de contraindicação absoluta para doação ${ }^{(16)}$, dúvidas quanto aos exames a serem realizados para o diagnóstico de $\mathrm{ME}^{(15,28)} \mathrm{e}$ a insegurança nos cuidados específicos na manutenção do potencial doador (sinais vitais ideais, hipotermia, volume de diurese, glicemia, entre outros) ${ }^{(20)}$ e baixo índice de capacitaçôes no tema ${ }^{(20,21)}$.

São visíveis fragilidades considerando que os dados apontam obstáculos em validar o potencial doador, bem como constatar quais são contraindicaçôes absolutas para doação de órgão ${ }^{(20)}$. Em relação às contraindicaçôes, profissionais de saúde intensivistas salientaram a sepse como contraindicação absoluta $^{(20)}$.

Outra fragilidade evidenciada nessa categoria foi o baixo índice de profissionais capacitados. Um dos estudos ${ }^{(16,28)}$ mostra que apenas $24,2 \%$ dos participantes receberam capacitação, enquanto $87,8 \%$ aprendeu na prática com os demais colegas. Outro, indicou que $67 \%$ dos participantes apontam ter pouca capacitaçáo nesse tema ${ }^{(18)}$. Ainda, outro artigo mostra que $46 \%$ dos participantes responderam errado às questôes quanto ao processo de doaçáo de órgãos e tecidos ${ }^{(19)}$. Importante destacar que esta é uma fragilidade singular, considerando que a falta ou a pouca capacitação nessa temática poderá gerar sérios efeitos adversos, como perda do potencial doador, insatisfação da equipe e problemas legais ${ }^{(1)}$.

\section{Categoria 2: Complexidade do processo de doação de órgãos: aspectos emocionais nesse processo}

No que se refere às fragilidades, foi possível compreender contratempos da equipe em estar diante do cuidado de um ser morto, com necessidades de cuidados intensivos devido à instabilidade hemodinâmica apresentada após a $\mathrm{ME}^{(16-18,22-26)}$. Além disso, foi discernido que os profissionais têm conhecimento da importância da doação, mas ao mesmo tempo expressam que deixam de lado este processo, muitas vezes, devido ao número insuficiente de recursos humanos, falta de apoio da instituiçáo, déficit de equipamentos e espaço físico ${ }^{(17,18,22)}$.

Aliado a essa realidade, tendem a priorizar o cuidado a pacientes vivos, com possibilidades terapêuticas, o que acarreta situaçóes de estresse e abalo emocional na equipe $^{(17,18,23-25)}$. No que se refere ao diagnóstico de ME, em razão da complexidade deste procedimento por questôes ética, moral, legal e cultural, estudos apontam a incerteza de alguns membros da equipe quanto a esse diagnóstico ${ }^{(23,25,26)}$. Diante disso, a atitude desses profissionais pode gerar conflitos e desconfiança do processo entre eles ${ }^{(19,25-27)}$.

Outra fragilidade apontada pelos enfermeiros foi o não reconhecimento de suas atividades no processo de doaçáo de órgãos e tecidos e não terem papel definido quanto aos cuidados por eles realizados ${ }^{(14)}$. Estes se sentem estressados e insatisfeitos ao estarem diante do cuidado ao potencial doador e família e não estão aptos e nem confortáveis para lidar com tal tarefa ${ }^{(22,23,25)}$.

A complexidade do cuidado frente ao acolhimento da família na comunicação do diagnóstico de $\mathrm{ME}$, comunicação da morte e elaboraçáo do luto, sinalizam o impacto emocional, medo, insegurança e despreparo para conduzir essas informaçôes ${ }^{(14,15)}$. Esses momentos sáo apontados como momentos difíceis de enfrentar e serem vivenciados, em especial pelo momento de velório no leito pela equipe e famíliai ${ }^{(22)}$.

No que se refere às potencialidades desta categoria, apesar do abalo emocional, os profissionais compreendem que a família precisa ser orientada sobre todas as etapas do processo de doaçáa ${ }^{(15)}$. Compreendem que a ME é equivalente a morte e que o potencial doador pode gerar vida ${ }^{(22)}$. Assimilam que este é um paciente complexo para ser cuidado o que exige um grande esforço da equipe, em especial do enfermeiro por estar diretamente envolvido no cuidado a esse paciente ${ }^{(19,22,24,25)}$.

Nesta categoria, foi identificado muito mais fragilidades do que potencialidades. Importante compreender que tais situaçôes são passíveis de gerar estresse, cansaço físico, emocional e erros no processo. Considerando que alguns artigos pontuam fortemente questōes de sobrecarga de trabalho, falta de apoio da gestão e déficit de equipamentos, é necessário que gestores olhem atentamente para essa realidade, uma vez que esse já é um processo que traz aspectos emocionais fortes por tratar com um ser morto com possibilidade de salvar vidas e pelo fato de a equipe estar junto a família por várias horas acolhendo essas pessoas no processo de luto ${ }^{(16,22)}$.

\section{DISCUSSÃO}

O Brasil, assim como diversos países, tem buscado constantemente melhorias no cenário da doação de órgãos. Países como Espanha, Portugal e Estados Unidos têm alcançado melhores resultados em número absoluto de doadores de órgãos ${ }^{(6)}$. Parte dos investimentos desses países está direcionado à capacitaçáo da equipe de saúde, aperfeiçoamento nas estruturas de saúde, além de programa de qualidade para rastrear oportunidades de progresso nas etapas do processo de doaçẫo ${ }^{(6,7)}$.

Nesta perspectiva, compreende-se que as informaçóes obtidas no estudo trazem evidências relevantes no que tange às fragilidades e potencialidades da equipe de saúde nas unidades 
de pacientes críticos quanto às etapas do processo de doação de órgãos e tecidos. Vale salientar que essas informaçóes, em sua maioria, foram de estudos desenvolvidos em 2018. Assim, destaca-se que tais fragilidades e potencialidades apresentadas são realidades recentes vivenciadas pela equipe. Considerando as informaçóes obtidas, compreende-se a necessidade de aprimorar e melhorar condiçôes de trabalho, educação permanente e apoio dos gestores à equipe de saúde que atua nesse cenário, no sentido de promover segurança, efetividade e qualidade das atividades e açóes de cuidado em todas as etapas do processo de doação de órgãos e tecidos.

No que se refere às evidências para melhores práticas, a categoria conhecimento da equipe traz implícito o conhecimento dos participantes do estudo para conduzir o diagnóstico de morte encefálica, em especial, para reconhecer os critérios que impedem a abertura deste diagnóstico, além do tempo adequado para realizaçáo dos exames ${ }^{(14-16)}$. No contexto do diagnóstico de ME, agilidade para identificar sinais clínicos de ME, bem como segurança para reconhecer cada fase desse diagnóstico são premissas fundamentais para avanços, segurança, ética e legalidade do processo. A legislação vigente determina que, em adultos, o intervalo entre os exames do diagnóstico de ME devem ser de uma hora ${ }^{(1)}$. Para agilizar esse diagnóstico e a validaçáo do potencial doador, diretrizes foram criadas para apoiar os profissionais ${ }^{(3)}$. Autores apontam que esse diagnóstico deve ser realizado de maneira segura, efetiva e com o tempo menor possível no sentido de minimizar o estresse da equipe e família. $\mathrm{O}$ ideal é que não ultrapasse o tempo previsto na legislação ${ }^{(2,22)}$.

Outro indicativo significativo, o qual é capaz de oportunizar mudanças na prática após aprimoramento da equipe, é a validação do potencial doador. A validação do potencial doador de órgãos e tecidos está descrita em diretrizes da AMIB, a qual consiste na avaliaçáo detalhada de indivíduos com presença de lesão encefálica de causa conhecida por meio de uma avaliação clínica criteriosa, exame físico minucioso, levantamento de informaçôes clínicas, laboratoriais, radiológicas, exclusão de riscos de transmissão de doenças (janela imunológica), descarte de contraindicaçôes absolutas e instabilidade hemodinâmica (hipovolemia, choque, parada cardíaca) ${ }^{(1,3)}$. As ações de validação e cuidados a este paciente exigem da equipe conhecimento, habilidade e sobretudo o raciocínio clínico no sentido de comparar dados clínicos, com exame físico e informaçôes obtidas junto a família para que possa ser definido a validaçáo do paciente como potencial doador. O domínio para proceder com exame físico, avaliar exames de bioquímica e controlar alteraçóes hemodinâmicas são fundamentais para assegurar efetividade e minimizar complicaçóes posteriores aos receptores, em razáo de que doadores com instabilidade hemodinâmica e/ou complicaçôes já instaladas podem acarretar em complicaçóes no pós-transplante ${ }^{(3,29)}$.
Na perspectiva da segurança deste processo, é fundamental que a equipe tenha respaldo legal e científico para validar o potencial doador, uma vez que a equipe transplantadora aceitará os órgãos do doador baseado nas informaçôes repassadas pelos profissionais das unidades de críticos que legitimaram este paciente como um potencial doador. Assim, é necessário que esta equipe possa rastrear dados relacionados ao histórico de saúde pregresso e atual, atentar para qualquer alteração durante o exame físico ou a qualquer detalhe que julgar importante mencionado pela família ${ }^{(4)}$.

Nesta perspectiva, o enfermeiro enquanto agente de cuidados integrais ao potencial doador exerce papel fundamental em rastrear possíveis alteraçôes físicas por meio do exame físico, alteraçôes hemodinâmicas que surgem ao longo do cuidado de enfermagem, além de investigar junto à família quanto ao risco da janela imunológica e intercorrências de saúde que possam ter acontecido e inviabilizem a doação ${ }^{(1)}$. O rastreamento de possíveis alteraçóes clínicas e sociais do potencial doador assegura um processo de qualidade e segurança, em especial ao receptor ${ }^{(3,30)}$.

Ainda na categoria conhecimento, as evidências direcionam a necessidade de gestores institucionais $\mathrm{e}$ governamentais criarem planos de educação permanente junto aos profissionais. Oito estudos mencionam de maneira direta ou indireta a necessidade de investimento em capacitação nesta temática ${ }^{(14-16,18-21,26)}$. A educação permanente em saúde é o caminho para a melhoria e o aprimoramento do sistema de transplante ao promover transformaçóes para a qualidade dos serviços. As açôes educativas devem estar embasadas nas reais necessidades de cada equipe em cada instituição. Para tanto, é importante o engajamento da equipe de saúde, bem como comprometimento dos gestores para efetivá-las ${ }^{(31,32)}$.

Assim, compreende-se a necessidade de um olhar cauteloso dos governantes em propor estratégias educacionais a esses profissionais. A legislação vigente orienta que profissionais médicos devem ter, no mínimo, participado de 10 diagnósticos de ME para serem considerados aptos para atuar nesse processo. Quanto aos outros profissionais da equipe, a determinaçáo é de no mínimo 42 horas de treinamento antes de ingressar na assistência ao potencial doador de órgãos e tecidos ${ }^{(1)}$.

Nos últimos três anos, houve um aumento superior a 25\% dos potenciais doadores notificados as Centrais Estaduais de Transplante, além de aumento no número de doadores efetivos de $12 \%{ }^{(7)}$. Esses dados mostram avanços importantes no cenário da doação. Assim como, a importância da capacitação da equipe quanto a esse diagnóstico, em especial para prevenir desconfiança no processo e questôes éticas e legais que possam surgir. O diagnóstico de ME requer pessoas treinadas e habilitadas, que devem ter completo compromisso em cada etapa deste diagnóstico ${ }^{(1)}$.

Diante da demanda de atividades que a equipe desenvolve neste processo, torna-se necessário que sejam apoiados 
por dirigentes das instituiçôes, considerando que estudos pontuam como uma das principais fragilidades a estrutura precária das instituiçóes de saúde. As principais dificuldades encontradas foram quanto ao déficit de profissionais, espaço físico e equipamentos. Tais situaçôes, além de causar estresse à equipe, podem gerar atraso no andamento das etapas do processo, eventos adversos, insatisfação e insegurança à família. Família enlutada insatisfeita com o atendimento tende a potencializar o estresse e os conflitos entre a equipe $e^{(9,10,18)}$.

Neste sentido, destaca-se a importância de protocolos institucionais para garantir apoio à equipe e uniformização de procedimentos e açôes aplicados a cada etapa do processo de doação. Programas de doação de órgáos bem administrados e mantidos em instituiçôes de saúde são essenciais para o sucesso dos transplantes de órgãos ${ }^{(33-34)}$. Além de apoiar a equipe quanto às ambivalências ética, legal e moral, em especial no cuidado ao paciente morto quando há tantos outros pacientes vivos para serem cuidados ${ }^{(18,23,24,26)}$, questóes éticas e legais ligadas ao processo de doação de órgãos e transplantes tem despertado frequentemente ampla discussão no meio científico nos últimos tempos ${ }^{(34-36)}$.

Nesta perspectiva, compreende-se como importante que a equipe possa ser escutada e percebida dentro das singularidades de cada ser humano e profissional quanto as suas limitaçóes, aspectos emocionais e estressores vividos neste processo. Há que ser reconhecido pelos órgãos governamentais, não governamentais e gestores que este processo é vivenciado por cada membro da equipe de maneira ímpar, considerando suas crenças, cultura, religiosidade, preceitos éticos e morais. Sugere-se que a equipe diretiva formule encontros frequentes para conhecer tal realidade, ao mesmo tempo em que possam criar grupos de apoio a esses profissionais. Esse apoio deve estar embasado em princípios da ética e bioética, no sentido de promover segurança, apoio, acolhimento e respeito à família do potencial doador ${ }^{(37-38)}$.

Importante compreender que a equipe está diante de um paciente morto, com condiçóes de ajudar outras pessoas por meio da doação. Paciente, cujo corpo é mantido artificialmente, mas com características de haver vida. Alguns estudos apontam divergência de opinióes entre a equipe quanto ao diagnóstico de $\mathrm{ME}$, decisão em reanimar o potencial doador diante de uma parada cardíaca e credibilidade do sistema de transplante $e^{(19,20,23,24)}$.

Consoante a esta discussão, há evidências quanto ao abalo emocional enfrentado pela equipe, os estudos apontam dificuldades e insegurança em comunicarà família sobre a morte ao término do diagnóstico de morte encefálica. Dessa forma, foi possível compreender o sofrimento e a angústia da equipe em lidar com tais atividades como informar sobre a abertura do diagnóstico de ME, manutençấo do corpo do doador para ajudar outras pessoas e comunicar a morte à família ${ }^{(19,22,24,25)}$. A comunicação da equipe de saúde junto à família nas etapas do processo de doação de órgáos e tecidos, é considerado uma das etapas mais complexas e difíceis, sendo imprescindível a capacitação desses profissionais para estarem com a família nesse momento, além de promover o autoconhecimento para saber lidar com o significado da morte, sofrimento e a dor da perda ${ }^{(39-40)}$.

O apoio emocional e psicológico promovido pela equipe de saúde aos familiares deve acontecer em todos os momentos da hospitalizaçấo, mas principalmente na iminência de morte e na confirmaçáo desta ${ }^{(40-41)}$. Para promover tal atividade de cuidado, o profissional deve estar preparado e disponível para escutar ativamente. $\mathrm{O}$ acolhimento envolve empatia, compaixão e amor para com o próximo, valorizando o encontro com o outro, por meio de uma postura ética e respeitosa ${ }^{(41)}$.

Nesta perspectiva, compreende-se que o apoio emocional à família seja realizado de maneira segura e efetiva, com o mínimo de danos possíveis para a família e para a equipe. Sugere-se que o profissional desenvolva capacitação em comunicação em situaçôes críticas e processo de morte e morrer, em que terão contato com ferramentas de comunicação, etapas do luto e relaçáo de ajuda. Estando respaldados para conduzir a situação crítica e ajudar a família diante de sentimentos de dor e fases do luto ${ }^{(38-39)}$. Vale salientar que nesse estudo as evidências apontam a necessidade de fortalecer a equipe para o apoio emocional à família no processo de luto.

\section{CONCLUSÃO}

No que se refere às potencialidades e fragilidades vivenciadas pela equipe de saúde nas unidades de pacientes críticos, o maior destaque quanto às fragilidades foi a pouca capacitaçáo da equipe, gerando estresse e abalo emocional para lidar com as etapas do processo de doação. Além disso, o estresse pode ser gerado pelo medo e risco de ocorrer eventos adversos por náo estarem aptos para lidar com todas as atividades impostas pelo processo de doaçáo de órgãos e tecidos. Pontua-se como outras fragilidades: pouca habilidade em conduzir a manutençáo do potencial doador direcionado a cuidados específicos; despreparo para validar a contraindicação absoluta a doação e insegurança em lidar com a comunicação junto à família e processo de luto.

Destaca-se que as dificuldades para lidar com a precariedade das estruturas físicas, falta de apoio dos gestores institucionais, conflitos da equipe sobre a condução do processo de doaçáo, divergência quanto ao diagnóstico de $\mathrm{ME}$ e cuidados ao ser morto foram outras fragilidades evidenciadas no estudo.

No que se refere às potencialidades, houve maior destaque ao conhecimento para identificação das causas de não abertura do protocolo de ME; reconhecimento do tempo adequado para realização dos exames e as etapas deste diagnóstico. Ainda, o reconhecimento dos profissionais do potencial doador como um ser que poderá gerar novas vidas e o direito 
da família em ser informada sobre todas as etapas do processo de doação de órgãos e tecidos.

Assim, as evidências do estudo apontam a necessidade do comprometimento dos gestores para promover açóes de educação permanente que venham a englobar o conhecimento destes profissionais no sentido de propor segurança e apoio à equipe, repercutindo em um sistema de doação efetivo e seguro.

\section{REFERENCES}

1. Decreto n. 9.175, de 18 de outubro de 2017 (BR) [Internet]. Regulamenta a Lei n. 9.434, sancionada em 4 de fevereiro de 1997, para tratar da disposição de órgáos, tecidos, células e partes do corpo humano para fins de transplante e tratamento. Diário Oficial da União. 18 out. 2017 [access at: Apr. 07, 2020]. Available at: https://presrepublica.jusbrasil.com.br/ legislacao/511312696/decreto-9175-17.

2. Vieira MS, Nogueira LT. The work process in the context of organ and tissue donation. Rev Enferm [Internet]. 2015 [access at: Apr. 07, 2020];23(6):82531. Available at: https://www.e-publicacoes.uerj.br/ index.php/enfermagemuerj/article/view/11744. http:// dx.doi.org/10.12957/reuerj.2015.11744.

3. Westphal GA, Garcia VD, Souza RL, Franke CA, Vieira KD, Birckholz VRZ, et al. Guidelines for the assessment and acceptance of potential brain-dead organ donors. Rev Bras Ter Intensiva [Internet]. 2016 [access at: Apr. 07, 2020];28(3):220-55. Available at: https://www. ncbi.nlm.nih.gov/pubmed/27737418. http://dx.doi. org/10.5935/0103-507X.20160049.

4. Freirel ILS, Vasconcelos QLDAQ, Torres GV, Araújo EC, Costa IKF, Melo GSM. Structure, process and outcomes of organ and tissue donation for transplantation. Rev Bras Enferm [Internet]. 2015 [access at: Apr. 07, 2020];68(5):555-63. Available at: https://www. scielo.br/scielo.php?script=sci arttext\&pid=S003471672015000500837\&lng=pt\&tlng=pt. http://dx.doi. org/10.1590/0034-7167.2015680511i.

5. Longuiniere ACF, Lobo MP, Leite PL, Barros RCS, Souza AN, Vieira SNS. Knowledge of critical care nurses about the process of brain death diagnosis. Rev Rene [Internet]. 2016 [access at: Apr. 07, 2020];17(5):6918. Available at: http://periodicos.ufc.br/rene/article/ view/6208/pdf. http://dx.doi.org/10.15253/21756783.2016000500015.

6. Knihs NS, Roza BA, Schirmer J, Ferraz AS. Application of Spanish quality instruments about organ donation and tranplants validated in pilot hospitals in Santa Catarina. J Bras Nefrol [Internet]. 2015 [access at: Apr. 07, 2020];37(3):323-32. Available at: https:// www.scielo.br/pdf/jbn/v37n3/en 0101-2800jbn-37-03-0323.pdf. http://dx.doi.org/10.5935/01012800.20150052.

7. Associação Brasileira de Transplante de Órgãos (BR). Registro Brasileiro de Transplantes. Dados númericos da doação de órgáos e transplantes realizados por estado e instituição no período: janeiro/setembro 2018. São Paulo: Associação Brasileira de Transplante de Órgãos; 2018 [access at: Apr. 07, 2020]. Available at: http:// www.abto.org.br/abtov03/Upload/file/RBT/2018/ rbt2018-let-3t.pdf.

8. Barreto BS, Santana RJB, Nogueira EC, Fernandez BO, Brito FPG. Factors associated with refusal to donate organs in the state of Sergipe, Brazil. Rev Bras Pesq Saúde [Internet]. 2016 [access at: Apr. 07, 2020];18(3):408. Available at: https://pdfs.semanticscholar. org/20be/3a82c41c7b4359f2f4ecae261e9e5a11e1cf. pdf.

9. Bonetti CE, Boes AA, Lazzari DD, Busana JA, Maestri E, Bresolin P. Organ and tissue donation and reasons for its non-realization. J Nurs UFPE on line [Internet]. 2017 [access at: Apr. 07, 2020];11(Suppl. 9):3533-41. Available at: https:// periodicos.ufpe.br/revistas/revistaenfermagem/article/ view/234483. https://doi.org/10.5205/1981-8963v11i9a234483p3533-3541-2017.

10. Passoni R, Padilha EF, Hofstatter LM, Ansolin AGA, Silva EAA. Clinical-epidemiological elements of family interviews for donation of organs and tissues. Enferm Glob [Internet]. 2017 [access at: Apr. 07, 2020];16(2):143-53. Available at: https://revistas. um.es/eglobal/article/view/234831/209821. http:// dx.doi.org/10.6018/eglobal.16.2.234881.

11. Leite NF, Maranhão TLG, Farias AA. Multiple organ procurement: the process challenges for health professionals and relatives. Id on Line Rev Multidisciplinar e de Psicologia [Internet]. 2017 [access at: Apr. 07, 2020];11(34):246-70. Available at: https:// idonline.emnuvens.com.br/id/article/view/687/967. http://dx.doi.org/10.14295/idonline.v11i34.687.

12. Moher D, Liberati A, Tetzlaff J, Altman DG, The PRISMA gROUP. Preferred reporting items for systematic reviews and meta-analyses: The PRISMA statement. International Journal of Surgery [Internet]. 2010 [access at: Apr. 07, 2020];8(5):336-41. Available at: $\quad$ https://www.sciencedirect.com/science/article/ pii/S1743919110000403?via\%3Dihub. https://doi. org/10.1016/j.ijsu.2010.02.007.

13. Melnyk BM, Fineout-Overholt E. Making the case for evidence-based practice. Evidence-based practice in nursing $\&$ healthcare. A guide to best practice. $2^{\text {a }}$ ed. United States: Wolters Kluwer; 2011. 
14. Masoumian Hoseini ST, Manzari Z, Khaleghi I. ICU Nurses' knowledge, attitude, and practice towards their role in the organ donation process from brain dead patients and factors influencing it in Iran. Int J Org Transplant Med [Internet]. 2015 [access at: Apr. 07, 2020];6(3):10513. Available at: https://www.ncbi.nlm.nih.gov/pmc/ articles/PMC4545304/pdf/ijotm-6-105.pdf.

15. Doria DL, Leite PMG, Brito FPG, Brito GMG, Resende GGS, Santos FLLSM. Nurses knowledge in the process of organ donation. Enferm Foco [Internet]. 2015 [access at: Apr. 07, 2020];6(1/4):31-5. Available at: http://revista.cofen.gov.br/index.php/enfermagem/ article/viewFile/573/255.

16. Vesco NL, Nogueira CS, Lima RF, Souza VN, Brasil BMBL, Viana CDMR. Nursing knowledge in organ and tissue for transplant donor potential maintenance. J Nurs UFPE on line [Internet]. 2016 [access at: Apr. 07, 2020];10(5):161524. Available at: https://periodicos.ufpe.br/revistas/ revistaenfermagem/article/view/11157. https://doi. org/10.5205/1981-8963-v10i5a11157p1615-1624-2016.

17. Costa IF, Netto JJM, Brito MCC, Goyanna NF, Santos TC, Santos SS. Weaknesses in the care for potential organ donors: the perception of nurses. Rev Bioética [Internet]. 2017 [access at: Apr. 07, 2020];25(1):13037. Available at: https://www.scielo.br/pdf/bioet/ v25n1/en_1983-8042-bioet-25-01-0130.pdf. http:// dx.doi.org/10.1590/1983-80422017251174.

18. Kentish NB, Duranteau J, Montlahuc C, Charpentier J, Martin LL, Joseph L, et al. Clinicians' perception and experience of organ donation from braindead patients. Critical Care Medicine [Internet]. 2017 [access at: Apr. 07, 2020];45(9):1489-99. Available at: https://journals.lww.com/ccmjournal/ Abstract/2017/09000/Clinicians Perception and Experience of Organ.9.aspx. https://doi.org/10.1097/ CCM.0000000000002581.

19. Lomero MDM, Jiménez-Herrera MF, Rasero MJ, Sandiumenge A. Nurses' attitudes and knowledge regarding organ and tissue donation and transplantation in a provincial hospital: a descriptive and multivariate analysis. Nurs Health Sci [Internet]. 2017 [access at: Apr. 07, 2020];19(3):322-30. Available at: https:// onlinelibrary.wiley.com/doi/epdf/10.1111/nhs.12348. https://doi.org/10.1111/nhs.12348.

20. Cunha DSP, Lira JAC, Campelo GVS, Ribeiro JF, Silva FAA, Nunes BMVT. Brain death and organ maintenance: knowledge of intensive care professionals. J Nurs UFPE on line [Internet]. 2018 [access at: Apr. 07, 2020];12(1):51-8. Available at: https:// periodicos.ufpe.br/revistas/revistaenfermagem/article/ view/25130. https://doi.org/10.5205/1981-8963v12i1a25130p51-58-2018.
21. Alves NCC, Oliveira LB, Santos ADB, Leal HAC, Sousa TMF. Management of patients in brain death. J Nurs UFPE on line [Internet]. 2018 [access at: Apr. 07, 2020];12(4):953-61. Available at: https:// periodicos.ufpe.br/revistas/revistaenfermagem/article/ view/110145/28647. https://doi.org/10.5205/19818963-v12i4a110145p953-961-2018.

22. Aredes JS, Firmo JOA, Giacomin KC. Deaths that save lives: the complexities of medical care for patients with suspected brain death. Reports in Public Health. [Internet]. 2018 [access at: Apr. 07, 2020];34(11):e000661718. Available at: https:// www.scielo.br/pdf/csp/v34n11/1678-4464-csp-3411-e00061718.pdf. $\quad$ https://doi.org/10.1590/0102311X00061718.

23. Victorino JP, Mendes KDS, Westin UM, Magro JTJ, Corsi CAC, Arena Aventura CA. Perspectives toward brain death diagnosis and management of the potential organ donor. Nurs Ethics [Internet]. 2018 [access at: Apr. 07, 2020];26(6):11886-96. Available at: https://journals.sagepub.com/doi/ pdf/10.1177/0969733018791335. $\quad \underline{\text { https://doi. }}$ org/10.1177/0969733018791335.

24. Magalhães ALP, Erdmann AL, Sousa FGM, Lanzoni GMM, Silva EL, Mello ALSF. Meaning of nursing care to brain dead potential organ donors. Rev Gaúcha Enferm [Internet]. 2018 [access at: Apr. 07, 2020];39:e2017-0274. Available at: https://www. scielo.br/pdf/rgenf/v39/en 1983-1447-rgenf-3901-e2017-0274.pdf. http://dx.doi.org/10.1590/19831447.2018.2017-0274.

25. Moghaddam HY, Manzari ZS, Heydari A, Mohammadi E. Explaining nurses' experiences of caring for brain dead patients: a content analysis. Electron Physician [Internet]. 2018 [access at: Apr. 07, 2020];10(8):7205-16. Available at: $\quad$ https://www.ncbi.nlm.nih.gov/pmc/articles/ PMC6122867/. http://dx.doi.org/10.19082/7205.

26. Moghaddam HY, Manzari ZS, Heydari A, Mohammadi E, Khaleghi I. The nursing challenges of caring for braindead patients: a qualitative study. Nurs Midwifery Stud. [Internet]. 2018 [access at: Apr. 07, 2020];7(3):11621. Available at: http://www.nmsjournal.com/article. asp? issn $=2322-1488$; year $=2018$; volume $=7$;issue $=3$; spa ge $=116$; epage $=121$; aulast $=$ Moghaddam. http: $/ / \mathrm{dx}$.doi. org/ 10.4103/2322-1488.235638.

27. Mutlu V, Utku T. Knowledge and attitude toward brain death and organ donation among anesthesiology and reanimation professionals. Transplantation proceedings [Internet]. 2019 [access at: Apr. 07, 2020];51:2163-66. Available at: https://www.sciencedirect.com/science/ article/abs/pii/S0041134518317299. https://doi. org/10.1016/j.transproceed.2019.01.168. 
28. Lawson MM, Mooney CJ, Demme RA. Understanding of brain death among health-care professionals at a transplant center. Progress in Transplantation [Internet]. 2019 [access at: Apr. 07, 2020];29(3):25460. Available at: https://journals.sagepub.com/ doi/10.1177/1526924819855054. http://doi. org/10.1177/1526924819855054.

29. Bedenko RC, Nisihara R, Yokoi DS, Candido VM, Galina I, Moriguchi RM, et al. Analysis of knowledge of the general population and health professionals on organ donation after cardiac death. Rev Bras Ter Intensiva (Online) [Internet]. 2016 [access at: Apr. 07, 2020];28(3):285-93. Available at: https://www.scielo. br/pdf/rbti/v28n3/en 0103-507X-rbti-20160043.pdf. http://dx.doi.org/10.5935/0103-507X.20160043.

30. Castelli I, Costa Júnior AL. Health professionals and the diagnosis of encephalic death: a review. Rev Espacios [Internet]. 2017 [access at: Apr. 07, 2020];39(7):6-17. Available at: http://www.revistaespacios.com/ a18v39n07/a18v39n07p06.pdf.

31. Signor E, Silva LAA, Gomes IEM, Ribeiro RV, Kessler M, Weiller TH, et al. Continued health education: challenges for management in public health. REUFSM [Internet]. 2015 [access at: Apr. 07, 2020];5(1):1-11. Available at: http://dx.doi. org/10.5902/2179769214766. https://periodicos. ufsm.br/reufsm/article/view/14766/pd.

32. Pereira LA, Silva KL, Andrade MFLB, Cardoso ALF. Permanent health education: a possible practice. J Nurs UFPE on line [Internet]. 2018 [access at: Apr. 07, 2020];12(5):1469-79. Available at: https:// periodicos.ufpe.br/revistas/revistaenfermagem/ article/viewFile/231116/29010. https://doi. org/10.5205/1981-8963-v12i5a231116p1469-14792018f.

33. Magalhães ALP, Lanzoni GMM, Knihs NS, Silva EL, Erdmann AL. Patient safety in the process of organ and tissue donation and transplant. Cogitare Enferm [Internet]. 2017 [access at: Apr. 07, 2020];(22)2:e45621. Available at: http://www.saude. ufpr.br/portal/revistacogitare/wp-content/uploads/ sites/28/2017/04/45621-200937-1-PB.pdf. https:// doi.org/10.5380/ce.v22i1.45621.

34. Wojda TR, Stawicki SP, Yandle KP, Bleil M, Axelband J, Wilde-Onia R, et al. Keys to successful organ procurement: an experience-based review of clinical practices at a high-performing health-care organization. Int J Crit Illn Inj Sci [Internet]. 2017 [access at: Apr. 07, 2020];7(2):91-100. Available at: http://www.ijciis. org/article. asp?issn $=2229-5151$; year $=2017$; volume $=$ 7; issue $=2 ;$ spage $=91 ;$ epage $=100$; aulast $=$ Wojda.$\quad$ http: $/ /$ dx.doi.org/10.4103/IJCIIS.IJCIIS 3017.

35. MacDonald SI, Shemie SD. Ethical challenges and the donation physician specialist: a scoping review. Transplantation [Internet]. 2017 [access at: Apr. 07, 2020];10(5):S27-S40. Available at: https://journals.lww. com/transplantjournal/Fulltext/2017/05001/Ethical Challenges and the Donation Physician.3.aspx. http://dx.doi.org/10.1097/TP.0000000000001697.

36. Shemie SD, Simpson C, Blackmer J, MacDonald S, Dhanani S, Torrance S. Ethics guide recommendations for organ-donation-focused physicians: endorsed by the Canadian Medical Association. Transplantation [Internet]. 2017 [access at: Apr. 07, 2020];101(5 Sppl 1):S41-S47. Available at: https://journals.lww. com/transplantjournal/Fulltext/2017/05001/Ethics Guide Recommendations for.4.aspx. http://dx.doi. org/10.1097/TP.0000000000001694.

37. Araújo MN, Massarollo MCKB. Ethical conflicts experienced by nurses during the organ donation process. Acta Paul Enferm [Internet]. 2014 [access at: Apr. 07, 2020];27(3):215-20. Available at: https://www.scielo. br/pdf/ape/v27n3/en 1982-0194-ape-027-003-0215. pdf. http://dx.doi.org/10.1590/1982-0194201400037.

38. Lima AAF. Donation of organs for transplant: ethical conflicts in the perception of professionals. $\mathrm{O}$ Mundo da Saúde [Internet]. 2012 [access at: Apr. 07, 2020];36(1):27-33. Available at: http://bvsms.saude. gov.br/bvs/artigos/mundo saude/doacao orgaos transplante conflitos eticos.pdf.

39. Macedo JL. As regras do jogo da morte encefálica. Rev Antropol [Internet]. 2016 [access at: Apr. 07, 2020];59(2):32-58. Available at: http://www.revistas. usp.br/ra/article/view/121932/120080. https://doi. org/10.11606/2179-0892.ra.2016.121932.

40. Meneses NP, Castelli I, Costa Junior AL. Brain death communication to family members: a survey with health professionals. Rev SBPH [Internet]. 2018 [access at: Apr. 07, 2020];21(1):192-217. Available at: $\quad$ http://pepsic.bvsalud.org/scielo.php?script=sci arttext\&pid $=$ S1516-08582018000100011.

41. Oliveira-Cardoso EA, Santos MA. Grupo de educação para a morte: uma estratégia complementar à formaçáo acadêmica do profissional de saúde. Psicol Ciênc Prof [Internet]. 2017 [access at: Apr. 07, 2020];37(2):500-14. Available at: https://www.scielo. br/pdf/pcp/v37n2/1982-3703-pcp-37-2-0500.pdf. http://doi.org/10.1590/1982-3703002792015. 